\section{Commentary: Toward achieving precision in the management of postcardiotomy failure}

\author{
Peter J. Altshuler, MD, and Pavan Atluri, MD
}

As the field of mechanical circulatory support evolves, postcardiotomy extracorporeal life support (PC-ECLS) is being increasingly recognized as a potentially invaluable fallback to postoperative patients with refractory cardiovascular failure. ${ }^{1}$ By the very nature of the treatment, however, PCECLS lacks the evidence-based backing that has come to dictate care in much of the remainder of the cardiovascular surgery domain. Many times, PC-ECLS is the "last line of defense" for a postcardiotomy patient, and the nuances involved in determining whether, when, who, and how make decisions regarding PC-ECLS initiation, maintenance, and discontinuation anything but straightforward. Prospective, randomized clinical trials to help answer many of these questions are limited when the control arm is fated to mortality; in the absence of these data, we must rely on up-to-date expert consensus.

This issue of the Journal features a joint position statement by the EACTS, ELSO, STS, and AATS on PCECLS in adults from leaders in extracorporeal life support. ${ }^{2}$ In a much-needed summary of the field, the authors provide concise and inclusive perspectives from the past and present to help guide all facets of clinical practice related to PCECLS. A comprehensive literature review reveals that even in the absence of highest-quality evidence, careful proactive planning and maintaining perspective regarding goals of care are key drivers in achieving optimal outcomes. Adhering to these tenets can help shape a carefully constructed consensus statement that can serve as an invaluable resource not only for cardiovascular surgeons and

From the Division of Cardiovascular Surgery, Department of Surgery, University of Pennsylvania, Philadelphia, Pa.

Disclosures: The authors reported no conflicts of interest.

The Journal policy requires editors and reviewers to disclose conflicts of interest and to decline handling or reviewing manuscripts for which they may have a conflict of interest. The editors and reviewers of this article have no conflicts of interest.

Received for publication Nov 20, 2020; revisions received Nov 20, 2020; accepted for publication Nov 20, 2020; available ahead of print Nov 30, 2020.

Address for reprints: Pavan Atluri, MD, Division of Cardiovascular Surgery, Department of Surgery, Hospital of the University of Pennsylvania, 3400 Spruce St, 6 Silverstein, Philadelphia, PA 19104 (E-mail: pavan.atluri@pennmedicine.upenn.edu).

J Thorac Cardiovasc Surg 2021;161:1332

$0022-5223 / \$ 36.00$

Copyright (c) 2020 by The American Association for Thoracic Surgery

https://doi.org/10.1016/j.jtcvs.2020.11.078

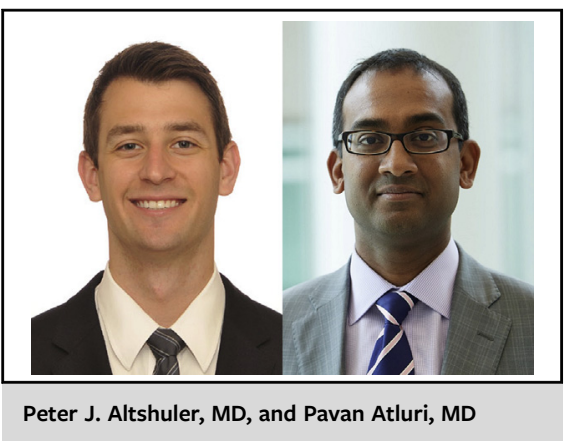

CENTRAL MESSAGE

The expert consensus on postcardiotomy extracorporeal life support provides a comprehensive and invaluable framework for guiding the care of patients with postcardiotomy failure.

intensivists practicing in centers actively using PC-ECLS, but also for all spectra of health care providers involved in the management of cardiac surgery patients.

Patients for whom PC-ECLS is even considered have little margin for error. Each facet of care related to PC-ECLS has the potential to be costly to both the patient and the health care team. The authors of this consensus statement are among the most experienced and knowledgeable in the field and understand better than any the precision required to achieve an optimal outcome. Unfortunately, robust evidence is limited in guiding providers, and precision in the absence of experience and high-quality data is difficult to achieve. The expert consensus statement presented therein serves to summarize best practice and provides the comprehensive framework to help achieve the best possible outcome for each and every patient considered for PC-ECLS. Quite simply, the 2020 EACTS/ELS/STS/ AATS expert consensus on postcardiotomy extracorporeal life support in adult patients is a must read.

\section{References}

1. Stretch R, Sauer CM, Yuh DD, Bonde P. National trends in the utilization of shortterm mechanical circulatory support: incidence, outcomes, and cost analysis. J Am Coll Cardiol. 2014;64:1407-15.

2. Lorusso R, Whitman G, Milojevic M, Raffa G, McMullan DM, Boeken U, et al. 2020 EACTS/ELSO/STS/AATS expert consensus on post-cardiotomy extracorporeal life support in adult patients. J Thorac Cardiovasc Surg. 2021; $161: 1287-331$. 